\section{Quantitative Estimation of the Fatty Acids of Olive Oil}

BEFORE making a systematic study of the fatty acid composition of Spanish olive oils it was necessary to devise a procedure which combined precision and accuracy with speed. In this brief account we present a summary of the results obtained in our work, involving (1) spectrophotometry and (2) quantitative paper chromatography of the saturated acids.

The spectrophotometric estimation of unsaturated fatty acids is carried out by the method recommended by the American Oil Chemists' Society ${ }^{1}$; saturated acids, separated according to Bertram ${ }^{2}$, are chromatographically determined by a procedure recently developed in this laboratory ${ }^{3}$. This procedure is an extension of that of Kaufmann and Nitsch ${ }^{4}$; the paper chromatograms are dipped in cupric acetate solution followed by treatment with rubianic acid to reveal the spots, the area of which is determined microphotometrically on photographs of the chromatograms.

The results of the analysis of a sample of olive oil from the 1957-58 erop in Bujalance (Cordoba) are compared in Table 1 with results on the same oil

Table 1. Component FatTy ACids (Pharcentage BY Weight) OF a SAMPLE OF OLIVE ON AS DETERMINRD BY DIFFERENT METHODS

\begin{tabular}{|c|c|c|c|c|}
\hline Acid & $\begin{array}{c}\text { Distillation } \\
\text { of } \\
\text { methyl } \\
\text { esters }\end{array}$ & $\begin{array}{l}\text { From } \\
\text { thiocyano- } \\
\text { gen value }\end{array}$ & $\begin{array}{l}\text { Method } \\
\text { Gas } \\
\text { chromato- } \\
\text { graphy }\end{array}$ & $\begin{array}{l}\text { Spectrophotometry } \\
\text { and paper } \\
\text { chromatography }\end{array}$ \\
\hline \multicolumn{5}{|l|}{ Saturated } \\
\hline Myristic & $0 \cdot 2$ & ? & - & - \\
\hline Palmitic & $8 \cdot \overline{9}$ & & $11 \cdot 7$ & $7 \cdot 7$ \\
\hline Stearic & $2 \cdot 4$ & $11 \cdot 9$ & $2 \cdot 4$ & $2 \cdot 5$ \\
\hline Arachidic & $0 \cdot 3$ & & - & 0.7 \\
\hline Behenic & - & & - & 0.8 \\
\hline \multicolumn{5}{|l|}{ Unsaturated } \\
\hline Hexadecenoic & $4 \cdot 7$ & ) & $1 \cdot 2$ & $76 \cdot 8$ \\
\hline $\begin{array}{l}\text { Oleic } \\
\text { Eicosenoic }\end{array}$ & $\begin{array}{r}66 \cdot 3 \\
4 \cdot 9\end{array}$ & $75 \cdot 5$ & $73 \cdot 5$ & 7 \\
\hline $\begin{array}{l}\text { Eicosenole } \\
\text { Linoleic }\end{array}$ & $\begin{array}{r}4 \cdot 9 \\
12 \cdot 3\end{array}$ & $12 \cdot 6$ & $\overline{11 \cdot 2}$ & $10 \cdot 9$ \\
\hline Linolenic & - & - & - & $0 \cdot 6$ \\
\hline
\end{tabular}

obtained $(a)$ by the traditional ester fractionation method $^{5}$, (b) from thiocyanogen values and (c) by the modern technique of gas chromatography at $170^{\circ}$ using polymerized ethylene glycol adipate as liquid phase and argon as carrier gas.

The results obtained by our combination of spectrophotometry and paper chromatography agree very well with those obtained by other methods; the absence of traces of myristic acid in the gas chromatographic analysis is rather surprising, though its absence from the paper chromatograms is not, since any present initially would have been degraded in the Bertram oxidation procedure. The small amount of behenic acid detected by paper chromatography would remain in the ester distillation residues and escape detection and it would also not be apparent in the gas chromatograms under the conditions employed. This acid has previously been identified by Spiteri $^{6}$ in olive oil; but the lignoceric acid also reported by him did not appear on our paper chromatograms. Linolenic acid, not revealed by gas chromatography, is apparently present as judged by the spectrophotometric evidence; but this cannot be taken as unequivocal proof of identity.

We feel that the method proposed by us will be of considerable value to workers who, lacking facilities for chromatography, require rapid analysis of olive oil for its main component acids. Unlike the time-consuming ester distillation procedure which requires somewhat more starting material and in which no saturated acid is usually unequivocally identified our method is relatively quick, saturated acids are identified, and the amount of oil required is quite small.

We wish to thank Dr. D. P. Cuthbertson, director of the Rowett Research Institute, Aberdeen, Scotland, for granting laboratory facilities to one of us (E. V.) which permitted the gas chromatographic analysis to be included.

$$
\begin{aligned}
& \text { J. Gractán } \\
& \text { E. Vroque } \\
& \text { Ma Pilar de la Maza }
\end{aligned}
$$

Instituto de la Grasa,

Seville,

Spain.

I "A.O.C.S. Tentative Method Cd 7-48" (Revised April, 1956). Official and Tentative Methods of the American Oil Chemists' Society, Chicago, Ill.

2 Bertram, S. H., Z. Untersuch. Lebensmittel, 55, 179 (1928).

Vioque, E., Vioque, A., and $\mathrm{M}^{\mathbf{2}}$ Pilar de la Maza, Grasas y Aceites, 9 , $168(1958)$.

4 Kaufmann, H. P., and Nitsch, W. H., Fette und Seifen, 56, 154 (1954) Hilditch, T. P., in "The Chemical Constitution of Natural Fats", 3rd ed. (London, Chapman and Hall, Ltd., 1956)

\section{Interaction between Thiourea and Insect Polyphenoloxidase}

Polyphenoloxidases of plant and animal origin are known to be inhibited by copper complexing sulphur compounds. When investigating the effect of thiourea on polyphenoloxidase of the wax-moth, Galleria mellonella L. (Lepidoptera), we noticed that degree of inhibition diminished during an aerobic incubation of the enzyme with the inhibitor and the substrate (catechol or $p$-cresol).

Experiments have been performed with homogenates from whole fully grown larvæ, and a typical course of oxygen uptake in the presence and absence of thiourea is shown in Fig. 1. The rate of uptake of oxygen by the uninhibited sample (indicated by the slope of curve $A$ ) diminishes steadily with the time of incubation which is a result of the inactivation of polyphenoloxidase ${ }^{1}$. On the other hand, the rates of oxidation in the presence of various concentrations of thiourea (slope of curves $B$ and $C$ ), which are initially low, increase considerably during the incubation, attain a certain maximum and finally drop as result of inactivation of the enzyme. This is better seen in Fig. 2 where the rates of uptake of oxygen are plotted against time of incubation. It is thus apparent that a release of the inhibition occurs during the incubation and that the inactivation of polyphenoloxidase which is known ${ }^{1}$ to accompany the enzymic oxidation of

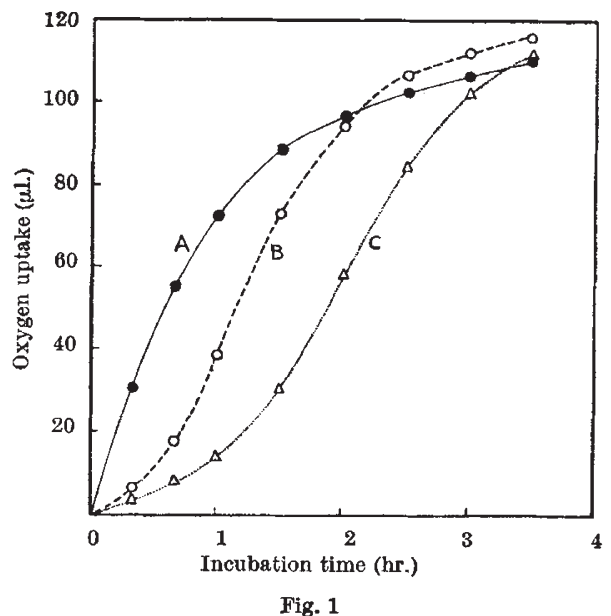

